\title{
ACERCA DO TEATRO E DOS FESTIVAIS ESTUDANTIS
}

\author{
Joaquim Gama \\ (...) não é propriamente fixar uma forma rígida de \\ representação - muito pelo contrário! (...) há que provocar e \\ explicitar alterações, e, em lugar dos atos de criação esporádicos e \\ anárquicos, deverão surgir processos de criação que empreendam, \\ indiferentemente, alterações graduais ou subidas.
}

Bertolt Brecht

Este texto é fruto das reflexões instauradas no $1^{\circ}$ Colóquio sobre Teatro Estudantil, realizado na Universidade de Sorocaba, no interior do Estado de São Paulo, em 18 de setembro de 2007, sob a curadoria da Profa. Dra. Ingrid Dormien Koudela. Nesse evento houve a participação dos alunos do curso de licenciatura de Teatro/Arte Educação, professores da universidade e artistas integrantes do $6^{\circ}$ Festival Estudantil SESI de Teatro.

O trabalho tem como objetivo apresentar as reflexões que surgiram durante o Colóquio e propor ações de âmbito artístico-pedagógico que possibilitem ao leitor pensar na importância do Teatro Estudantil e na organização dos festivais estudantis.

As questões que conduziram esta reflexão foram:

- Como se dá a formação dos atores no Teatro Estudantil?

-A instrumentalizaçãodo teatrona escola, muitas vezes, semoconhecimento pedagógico do fazer artístico, é presente também no Teatro Estudantil?

- Em que universo está circunscrito o Teatro Estudantil?

1Professor universitário de teatro da Universidade Sorocaba - SP e diretor do Grupo Experimental de Teatro - GET, do Teatro Humboldt - SP. Atualmente desenvolve pesquisas na área da pedagogia do teatro,em nível de pós-graduação, doutorado, na ECA/USP. 
$\mathrm{Na}$ perspectiva da última questão, Ingrid Koudela abriu o evento destacando as especificidades do Teatro Estudantil e do Teatro Amador. Em geral, a denominação Teatro Amador sempre causou polêmica. Alguns autores consideram tal nomenclatura pejorativa para o trabalho de artistas que realizam suas propostas cênicas às custas da boa vontade e do trabalho intenso dos participantes. Tal denominação, normalmente, vem acompanhada da idéia de uma produção com qualidade inferior às companhias profissionais de teatro e isso não pode ser tomado como regra. Sabe-se que muitos dos atores profissionais são oriundos do movimento de Teatro Amador e conseguiram se destacar justamente pela sua capacidade de experimentação e criação artística. É o que se observa nos dizeres de Paschoal Carlos Magno, “(...) um teatro só é autêntico quando revela ou leva à cena os autores de seu país, quando descobre, compara ou estimula os talentos novos e os jovens. Daí a importância do teatro amador" (In: FAYA, 2005, p. 177).

Aqui, cabe salientar que se a utilização do termo amador, atrelado ao teatro, sempre foi acompanhado de juízo de valor depreciativo e preconceituoso não podemos perder de vista que o Teatro Amador, notadamente por intermédio dos festivais, tiveram e têm a tarefa de propor, reinventar e criar novas combinações cênicas que não só trazem um frescor para o fazer teatral, como também realimentam as companhias profissionais.

Convém destacar que o Teatro Amador se configura como um laboratório de experiência e investigação teatral. Assim, possibilita também aos profissionais da área teatro lançar mão de propostas que já tenham sido experimentadas e colocadas à prova do público. $\mathrm{O}$ fato de trabalharem sob a égide da diversidade, os grupos amadores têm justamente um campo propício para investir na experimentação teatral o que resulta, conseqüentemente, numa maior liberdade de ação artística.

Já o Teatro Estudantil tem as mesmas possibilidades do fazer artístico do Teatro Amador, porém, está circunscrito no âmbito do universo estudantil. Enquanto o Teatro Amador congrega indivíduos dos mais variados níveis sociais, o Teatro Estudantil se caracteriza pela disposição de um grupo de estudantes que elegem o teatro como expressão e comunicação artística. Assim, claro está que o Teatro Estudantil se insere nas perspectivas do Teatro Amador, entretanto está voltado para estudantes e é vinculado a uma instituição de ensino. Vale insistir que o Teatro Estudantil não é Teatro Infantil, no entanto, pode ser realizado por crianças. Ele pode contemplar produções realizadas por crianças, mas não é a sua única configuração, nem tampouco se dirige apenas a uma platéia de crianças e/ou estudantil. 
Por esse viés, tanto o Teatro Amador como o Teatro Estudantil trazem possibilidades de lançar um olhar inovador e mais investigativo sobre a cena. Se, algumas vezes, confundimos Teatro Amador com o Teatro Estudantil, sem ter muita clareza de suas fronteiras, ambos são marcados por uma mesma característica: a busca por novas convenções teatrais (HIRSZMAN, 1980).

Dentro desse espectro, os festivais assumem um papel importante para a difusão de pesquisas cênicas e para o surgimento de novas dramaturgias. A descaracterização desse espaço pode se constituir num hiato irreparável para o teatro.

OTeatroEstudantil sempresemostrou ativoepresentenaculturabrasileira, e isso fica evidente nos diversos momentos da história do teatro brasileiro. No século XX, cabe destacar diversos movimentos, entre eles, o ocorrido na faculdade do Largo São Francisco, em São Paulo, na década de 50. Nesse espaço transitaram nomes significativos do teatro nacional, como o dramaturgo e encenador José Celso Martinez Correa - Zé Celso, que, hoje, dirige o Teatro Oficina.

É fundamental apontar que esse período foi marcado pela notoriedade do Teatro Estudantil. Em 1938, no Rio de Janeiro, surge o Teatro Estudantil do Brasil - TEB, fundado por Paschoal Carlos Magno. As propostas desse grupo foram iniciadas em 1933, ainda na Casa do Estudante do Brasil. Com a montagem de Hamlet, de William Shakespeare, o grupo propôs um novo padrão cênico e, junto com o grupo Os Comediantes, criado no mesmo ano, formam a linha de frente da renovação cênica no país (HIRSZMAN, 1980). O mesmo se seguiu com outros grupos como: o Teatro Acadêmico (1939), de Mário Brassini, transformado em Teatro Universitário - TU (com o apoio da União Nacional dos Estudantes, UNE); Teatro do Estudante de Pernambuco, TEP (1946); Teatro de Amadores de Pernambuco, TAP; Teatro Popular do Nordeste, TPN, sob o apoio de Hermilo Borba Filho.

Já em 1955, temos a criação do Centro Popular de Cultura da UNE CPC por todo Brasil. Nessa época, São Paulo registra o surgimento do Teatro Paulista do Estudante (1957), que se funde com o Teatro de Arena; A Oficina, que deu origem ao Teatro Oficina em 1959. Há ainda o Teatro da Universidade Católica - TUCA, na PUC/SP; o Teatro dos Universitários do Mackenzie TEMA; o Teatro do Sedes Sapientie - TESE (1965); o Teatro dos Universitários de São Paulo - TUSP, ligado ao DCE central da USP (1967).

No Rio de Janeiro, em 1965, temos o Teatro Universitário Carioca, TUCA/Rio, dirigido por Amir Haddad. Vale ainda relacionar diversos grupos que nasceram por outras regiões do Brasil e tiveram participações artísticas de relevância em vários festivais. 


\section{Urdimento}

${ }^{1} \mathrm{~A}$ Escola nas Férias é um projeto que se propõe oferecer uma série de experiências aos alunos, envolvendo diversos núcleos temáticos e atividades artísticas.

\section{O Programa Escola} da Família consiste em abrir as escolas da Rede Estadual de Ensino de São Paulo, aos finais de semana, transformando-as em centro de convivência, com atividades voltadas às áreas esportivas, culturais, de saúde e de trabalho.

\section{A Escola de Tempo} Integral tem como objetivo a aprendizagem baseada em vivências e experiências organizadas por meio de projetos ou temas geradores. Dáse ênfase a uma área ou a um tema do conhecimento como eixo de organização para o desenvolvimento das habilidades e competências dos alunos. Nesse caso, a arte se constitui num dos projetos aglutinadores do conhecimento e a conexão para o ensino. Destaca-se nessa proposta uma metodologia participativa que envolve a vida prática comunitária, a solução de problemas que inquietam ou estimulam a vida cotidiana dos alunos.
Durante o período da ditadura, o Teatro Estudantil, vindo das universidades, assumiu um papel de resistência política, transformando São Paulo no epicentro do movimento das produções estudantis. A partir dos festivais, essas produções se transformaram num dos mais importantes espaços de discussão política e artística.

Os festivais estudantis foram responsáveis, no Brasil, pela renovação da cena teatral, atingindo:

\section{(...) não apenas os meios expressivos do palco como, de modo} enfático, os padrões de gosto e de consumo da atividade teatral, ampliando consideravelmente os locais de oferta. Optando por um repertório que dificilmente um conjunto profissional ousaria montar, ofereceu ao espectador um grande leque de proposições artísticas. Do Shakespeare de 1938 chega-se ao Brecht de 1968, paulatinamente percorrendo as etapas artísticas mais significativas da arte cênica ocidental. (HIRSZMAN, 1980, p. 49-52)

O animador cultural, produtor, crítico, autor e diretor de teatro Paschoal Carlos Magno estruturou o primeiro Festival de Teatro Estudantil, no Recife, ainda na década de 40. Seus festivais iam além de uma programação de espetáculos vindos de todo o país; constituiam-se, acima de tudo, em encontros teatrais riquíssimos. Esses festivais promoviam inúmeras discussões, mesas redondas, aulas, palestras e exposições, cumprindo também a função pedagógica e didática na formação de público, com a intenção de despertar novos interessados no fazer teatral.

Hoje, os festivais de Teatro Estudantil possuem uma demanda de grupos oriundos de escolas de Educação Básica. Com a obrigatoriedade do ensino da Arte e a inclusão do teatro nas atividades extracurriculares, muitos grupos surgiram, tendo como atores crianças e adolescentes. Nesse sentido, o professor de teatro assume o papel de encenador e passa a ter como perspectiva a montagem de espetáculos. O processo de montagem de uma encenação torna-se o campo didático e experimental para a aprendizagem teatral.

Numa relação colaborativa, professores-encenadores e alunosatuantes buscam focalizar seus esforços na descoberta de novos modos de fazer teatro, em insights e em processos que se configuram num modo próprio para aprender e fazer teatro. 


\section{Urdimento}

Em São Paulo, nas escolas públicas, há vários grupos trabalhando a partir dessa perspectiva. Devem-se essas ações também às implementações realizadas pela Secretaria Estadual de Educação, que abrangem oficinas de teatro em Escolas de Tempo Integral, projetos desenvolvidos no período de férias e no programa Escola da Família ${ }^{2}$. Dentro desse conjunto de ações, destaca-se o lançamento de um portal eletrônico em julho de 2008, para arregimentar as propostas do projeto Escola em Cena. O objetivo é se apropriar dos recursos da multimídia para lançar ações artísticas e pedagógicas, que envolvem idas ao teatro e textos sobre o fazer teatral. O portal Currículo é cultura pretende atingir professores e alunos, propondo a ampliação dos espaços de aprendizagem dentro da escola ${ }^{3}$.

Dentro dessa visão é possível afirmar que a escola é um espaço de potencialidade para o fazer teatral. E mais, investir em iniciativas que promovam a montagem de espetáculos por estudantes, traz a oportunidade de ampliar as atividades teatrais dentro da escola, que, muitas vezes, estão circunscritas num universo meramente instrumental.

Observa-se, também, que, muitas vezes, o teatro na escola está presente apenas como instrumento para o ensino e a aprendizagem de conteúdos de outras disciplinas e é conduzido de forma autoritária, desvinculado da experiência artística dos alunos.

Desse modo, a perspectiva instrumental do teatro não precisa ser negada e pode ser ampliada já que o teatro é eficiente no processo de ensino e aprendizagem de determinados conteúdos escolares. Portanto, mesmo diante de uma proposta teatral instrumentalista, os alunos devem ser encorajados a contribuir com o processo de criação, trazendo, assim, para as cenas suas vivências e o universo social em que estão inseridos. Uma encenação com caráter instrumental não precisa limitar a preparação dos alunos-atuantes em mera repetição técnica que nada contribui para o momento e a necessidade do grupo. Os alunos-atuantes podem, sim, deixar de serem meros instrumentos para a realização de uma encenação e passarem a ser os criadores, co-autores do trabalho teatral.

Os procedimentos instaurados na construção das encenações podem combinar vários encaminhamentos pedagógicos, que vão desde jogos teatrais até improvisações. Pode-se e deve-se instaurar um espaço de experimentação que possibilite a investigação de novos modos de fazer teatro. Procedimentos oriundos do sistema de Jogos Teatrais, de Viola Spolin, contribuem para a fluência imaginativa dos participantes do grupo. Propostas que incluem a ludicidade e a descoberta, trazem para o trabalho a:
Em geral, uma parte do dia é destinada aos estudos das disciplinas que compõem o núcleo da matriz curricular nacional e a outra parcela do dia é destinada ao desenvolvimento de projetos.

Cabe dizer que uma avaliação mais atenta para essas propostas, indica problemas que dificultam a realização de trabalhos na área teatral. Esses problemas vão desde o escasso tempo destinado às aulas de Teatro até às condições físicas dos estabelecimentos de ensino.

${ }^{3} 0$ endereço eletrônico desse portal é culturaecurriculo. edunet.sp.gov.br. 
(...) alegria de representar, assinalando (...) que seria ridículo imaginar que alguém se dedica a jogar futebol para cumprir um dever patriótico de fortalecer o corpo. E define o encenador como um homem que se reúne com seu coletivo de trabalho não para fornecer respostas e soluções, mas para incentivar a pesquisa, a reflexão, a duvida, o questionamento permanente. (WEKWERTH, 1992, p. 14)

As investigações cênicas, surgidas dos jogos teatrais podem quebrar conceitos fechados, engessados, de modelos do teatro profissional. $\mathrm{Na}$ sistematização dos jogos teatrais, as discussões acerca do fazer teatral trazem aos atuantes o entendimento das atividades lançadas pelo professor-encenador e propiciam o debate sobre questões estéticas a serem assumidas na encenação.

Claro está que os jogos teatrais lidam com os conflitos de grupo como desafios a serem superados pelos atuantes. Um dos conflitos enfrentados pelos professores-encenadores, que trabalham com grupos sediados em escolas, é a distribuição de personagens entre os seus integrantes. Encenadores que elegem apenas um ator como protagonista, acabam com os conflitos de relacionamento, criando uma série de descontentamentos entre os outros atores. Muitas vezes, o diretor perde um tempo enorme buscando reconduzir o trabalho teatral e tentando encontrar saídas para o problema instaurado.

Outro aspecto a ser considerado é a atuação em coro, pois é uma proposta estética e pode se configurar como uma saída para o problema de distribuição de papéis dentro de um grupo. Para a autora Koudela,

(...) a forma coral é particularmente interessante no teatro (dança e música) com crianças, jovens e amadores, na medida em que potencialmente elimina a apropriação do personagem por um único ator, descaracterizando assim a perigosa noção de "talento", que facilmente conduz a comportamentos competitivos e exibicionistas. (KOUDELA, 1992, p. 85)

Com efeito, o que também não se pode negligenciar é que o trabalho teatral, realizado dentro das escolas, pelos grupos estudantis, deve dialogar com as propostas contemporâneas do teatro. Há uma tendência em criar uma cisão entre o teatro que se faz na escola e o teatro que se faz fora dela. Uma investigação teatral, dentro da escola, precisa contemplar também uma atitude política e artística que se coadunam com as propostas do teatro contemporâneo. Dentro dessa perspectiva, a experimentação e o distanciamento de velhas referências técnicas tornam o caminho bastante instigante. 
As propostas artísticas do Teatro Estudantil, provenientes de escolas de Educação Básica, podem surgir de inúmeras formas, que vão desde o contato com outros artistas até à ida ao teatro. Espetáculos assistidos pelos alunos-atuantes se configuram como um espaço também propício à aprendizagem artística.

Ao se pensar na organização de festivais estudantis, faz-se necessário refletir sobre o encaminhamento desses eventos:

- Se levarmos em conta que os grupos nem sempre têm disponível um palco à italiana e nem os aparatos de um teatro equipado, não seria interessante os festivais colocarem à disposição desses grupos locais diferenciados, como a rua, praças e outros locais possíveis de serem transformados em espaços cênicos?

- Como fazer para que os festivais estudantis realizem suas vocações de aprendizagem artística?

- Qual a importância de um corpo de jurados que dialoga com os grupos (atuantes/encenadores), ao invés de posturas conduzidas pelo julgamento e/ ou avaliações que são orientadas pelo teatro profissional?

- Será que a premiação de grupos é de fato a melhor forma de reconhecimento do trabalho dos grupos de Teatro Estudantil?

É preciso não perder de vista a possibilidade de troca e aprendizagem artística que os festivais oferecerem aos grupos. Seria fundamental se os grupos de Teatro Estudantil pudessem ter espaço para discutir suas pedagogias, suas propostas estéticas e suas visões sobre o teatro. É importante não só abrir espaços para discutir a recepção do trabalho pela platéia, efetivando o que as atuais pesquisas na área da pedagogia do teatro denominam como a leitura da obra teatral, mas também é significativo refletir sobre a construção estética de uma encenação e os seus desafios pedagógicos.

Os festivais estudantis podem primar por uma análise mais precisa dos encaminhamentos pedagógicos empregados pelos grupos, discutindo o impacto desses procedimentos na construção das cenas e nas suas estruturações espetaculares. Não se trata de julgar as encenações a partir dos critérios e valores artísticos oriundos do teatro profissional, mesmo porque nem sempre é possível enquadrar essas produções nos moldes do teatro profissional. O teatro dito profissional e o Teatro Estudantil devem estar em constante diálogo, mas ambos possuem especificidades que são determinantes para seus resultados teatrais. 
Assim sendo, parece mais estimulante estabelecer um espaço de diálogo entre os grupos e o corpo de jurados. Essa relação dialógica possibilita não só aos jurados uma maior compreensão do fazer teatral dos grupos, como também aos encenadores e atuantes explorarem a experiência teatral dos jurados. Dessa maneira, mobiliza os grupos de Teatro Estudantil mais para o desejo de investigação do que pela reprodução de uma pretensa convenção estética teatral correta.

Em face disso, há necessidade de criar outros espaços de aprendizagem dentro dos festivais, estabelecendo programações que envolvam oficinas, palestras e mesas-redondas. Esses espaços, com ênfase na pedagogia do teatro, tornam-se significativos para o domínio dos modos de produção teatral, para o aprimoramento das capacidades de expressão artística e para a compreensão de processos didáticos experimentados pelos grupos.

Já em relação à premiação dos grupos, faz algum sentido uma noite destinada à entrega de troféus? Não seria um paradoxo para os propósitos de coletividade, presentes nos grupos de estudantes, festivais que finalizam suas programações com festas hollywoodianas que imitam o Oscar?

Diante de uma diversidade enorme de produções, cada qual com suas proposições artísticas, como estabelecer o melhor trabalho? Sob qual ótica as premiações estariam fundadas? No projeto teatral do grupo? Na capacidade de comunicação com a platéia? Ou, mais uma vez, em critérios advindos do chamado teatro profissional?

Se o desejo é o incentivo à criação, não é mais interessante pensar em encerramentos que agreguem outras perspectivas? Por que não uma festa performática? Por que não a apresentação de um outro grupo de teatro que tenha ligação com os propósitos ou o tema do festival estudantil?

É bem verdade que, muitas vezes, as premiações oferecem aos grupos a oportunidade de serem reconhecidos não só fora do contexto estudantil, mas também dentro das suas instituições de ensino. São comuns os encenadores afirmarem que depois de serem premiados, os diretores de escola passam a valorizar mais suas atividades de teatro. Para esses grupos, o reconhecimento do seu trabalho é fundamental à sua continuidade. Afinal de contas a produção teatral está pautada na idéia de visibilidade. Todos fazem teatro na esperança de serem vistos e reconhecidos pelos seus desempenhos artísticos. Porém, em se tratando de um festival estudantil, talvez, a maior contribuição seja a divulgação dos grupos junto à imprensa, à comunidade local ou em outros setores da cultura. 
É interessante insistir em que diante do escasso lastro financeiro dos grupos de Teatro Estudantil, uma ajuda de custo por parte das instituições que promovem o evento é sempre bem vinda e contribui para a participação dos atuantes no festival.

Repensar os modos de produção dos grupos de Teatro Estudantil e a organização dos festivais, talvez, aproxime mais os envolvidos à etimologia latina da palavra festival - festvs, como encontro jovial, alegre, de intensidade criativa e comunicativa.

\section{Referências Bibliográficas}

BRECHT, Brecht. Diários de trabalho. Org. Herta Ramthum. Trad. Reinaldo Guarany, Porto Alegre: L\&PM, 1995.

Estudos sobre teatro. Rio de Janeiro: Nova Fronteira, 1978.

FAYA, Orleyd Rogéria Neves. Teatro paulista de amadores: 1964-1985 - a trajetória do movimento federativo nos 21 anos de ditadura militar no Brasil preâmbulo histórico - cultural. Dissertação de mestrado apresentada à ECA/ USP. São Paulo: ECA/USP, 2005.

FERNANDES, Silvia. Grupos teatrais - anos 70. Campinas: Ed. Unicamp, 2000. GAMA, Joaquim C. Moreira. Produto teatral: a velha nova história - experimento realizado com alunos do ensino médio. Dissertação de mestrado apresentado à ECA/USP. São Paulo: ECA/USO, 2000.

HIRSZMAN, Leon. CPC: arte para o povo e com o povo. Revista Ensaio, n. 3. Rio de Janeiro, 1980, p. 49-52.

KOUDELA, Ingrid Dormien. Texto e Jogo. São Paulo: Perspectiva, 1996. (org.). Um vôo brechtiano. São Paulo: Perspectiva, 1992. Brecht: um jogo de aprendizagem. São Paulo: Perspectiva, 1991.

SPOLIN, Viola. Jogos teatrais na sala de aula. Trad. Ingrid D. Kuodela. São Paulo: Perspectiva, 2007.

O jogo teatral no livro do diretor. Trad. Ingrid D. Kuodela. São Paulo: Perspectiva, 2004.

WEKWERTH, Manfred. Diálogo sobre a encenação - um manual de direção teatral. Trad. Reinaldo Mestrinel. São Paulo: 1992. 